\begin{tabular}{|c|c|}
\hline $\begin{array}{l}\text { Additional } \\
\text { Information }\end{array}$ & $\begin{array}{l}\text { NOTICE: this is the author's version of a work that was accepted for } \\
\text { publication in Ceramics International. Changes resulting from the } \\
\text { publishing process, such as peer review, editing, corrections, structural } \\
\text { formatting, and other quality control mechanisms may not be reflected in } \\
\text { this document. Changes may have been made to this work since it was } \\
\text { submitted for publication. A definitive version was subsequently } \\
\text { published in Ceramics International, Vol. 38, Issue 6, (August 2012). }\end{array}$ \\
\hline $\begin{array}{l}\text { Alternative } \\
\text { Location }\end{array}$ & http://dx.doi.org/ 10.1016/j.ceramint.2012.02.093 \\
\hline
\end{tabular}




\section{Accepted Manuscript}

Title: Fracture statistics of dental ceramics: Discrimination of strength distributions

Authors: Serkan Nohut, Chunsheng Lu

PII: $\quad$ S0272-8842(12)00208-8

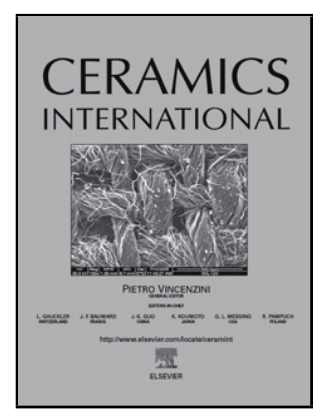

DOI: doi:10.1016/j.ceramint.2012.02.093

Reference: CERI 5118

To appear in: Ceramics International

Received date: $5-11-2011$

Revised date: 8-2-2012

Accepted date:

28-2-2012

Please cite this article as: S. Nohut, C. Lu, Fracture statistics of dental ceramics: Discrimination of strength distributions, Ceramics International (2010), doi:10.1016/j.ceramint.2012.02.093

This is a PDF file of an unedited manuscript that has been accepted for publication. As a service to our customers we are providing this early version of the manuscript. The manuscript will undergo copyediting, typesetting, and review of the resulting proof before it is published in its final form. Please note that during the production process errors may be discovered which could affect the content, and all legal disclaimers that apply to the journal pertain. 


\title{
Fracture statistics of dental ceramics: Discrimination of strength
}

\section{distributions}

\author{
Serkan Nohut ${ }^{\text {a }}$, Chunsheng Lu ${ }^{\text {b, * }}$ \\ ${ }^{a}$ Faculty of Engineering, Zirve University, Kizilhisar Kampusu, Gaziantep 27260, Turkey \\ ${ }^{\mathrm{b}}$ Department of Mechanical Engineering, Curtin University, Perth, WA 6845, Australia
}

\begin{abstract}
The Weibull distribution is the most widely used function in the reliability analysis and structural design of dental ceramics; however, it is still unclear whether Weibull distribution is always the most suitable one. With wide applications of dental ceramics, a special attention has been paid in discriminating their strength distributions. In this paper, three versatile functions, involving normal, log-normal and Weibull distributions, are applied to the analysis of ten strength data sets of dental ceramics with different compositions and the results are compared in terms of the Akaike information criterion and the Anderson-Darling test. It reveals that various microstructures and compositions in the investigated dental ceramics cause their strength distributions deviated from the Weibull distribution. The influence of microstructure induced fracture properties (multiple-modal flaw size distribution, $R$-curve behavior and subcritical crack growth) on strength distributions is discussed.
\end{abstract}

Keywords: B. Failure Analysis; C. Strength; D. Glass Ceramics; D. Porcelain; Statistical analysis

\footnotetext{
* Corresponding author. Tel.: +61 89266 4562; fax: +61 892662681 .

E-mail address: c.lu@curtin.edu.au (C. Lu).
} 


\section{Introduction}

Owing to their inertness, corrosion resistance and aesthetic properties, the use of ceramics in restorative and prosthetic dentistry is rapidly increasing. In determining the clinical success of ceramic restorations, however, the structural reliability of dental ceramics is a major factor due to the brittle trait [1]. This introduces the necessity to investigate the mechanical properties (e.g., strength, fracture toughness, etc.) and reliability of dental ceramics, which are normally polycrystalline solids and exist in glass form with various amounts and types of crystalline phases. According to glass-crystalline ratios, dental ceramics can be categorized into four main groups and a few subgroups [2]. Generally, the main challenge in the reliable design of dental ceramics is the exact estimation of their failure probabilities under prescribed loading and boundary conditions. The strength of a ceramic is inversely proportional to the square root of the critical size of crack-like defects that are randomly distributed in the material [3]. Due to the scatter of position, length and orientation of critical cracks, the strength of ceramics vary unpredictably from component to component, even if identical specimens are tested. Thus, in the design of dental ceramics, a probabilistic method is recommended [4-6]. Here, strength also depends on the stressed area or volume of the material because a larger area or volume increases the probability of existence of a critical flaw $[7,8]$.

The Weibull distribution is the most widely used function in describing strength data of ceramics [9-11]. For example, Quinn and Quinn [11] fitted the strength data of alumina, zirconia and two feldspathic porcelains with the Weibull distribution and then calculated their effective volumes in order to compare measured strengths from different test configurations. They concluded that the Weibull analysis has a strong theoretical basis and is of particular value in dental applications. There are also some cases, however, where the Weibull distribution fails to fit strength data of ceramics [12-16]. Danzer [12] reported that the 
Weibull theory is inconsistent in estimating the strength of small specimens because their effective volumes become less than the fracture origin. Several potential reasons that cause deviation from the Weibull statistics were introduced, such as the multi-modal flaw size distribution, $R$-curve behavior, and subcritical crack growth [13]. In terms of a minimum information criterion, strength data of $\mathrm{Si}_{3} \mathrm{~N}_{4}, \mathrm{SiC}$ and $\mathrm{ZnO}$ ceramics were fitted by normal and Weibull distributions [14]. It was shown that, compared to $\mathrm{Si}_{3} \mathrm{~N}_{4}$ and $\mathrm{SiC}$ ceramics, for which the Weibull distribution is the most suitable function, the normal distribution fits the strength data of $\mathrm{ZnO}$ better than the Weibull distribution. By using a larger class of probability models including the Weibull, normal, log-normal, gamma and generalized exponential distributions, Basu et al. [15] carried out the statistical analysis of strength data of monolithic $\mathrm{ZrO}_{2}, \mathrm{ZrO}_{2}$ $\mathrm{TiB}_{2}$ composites, glass and $\mathrm{Si}_{3} \mathrm{~N}_{4}$. Based on goodness-of-fit tests (the minimum $\chi^{2}$, the minimum Kolmogorov distance, and the maximum log-likelihood value), they reported that the gamma or log-normal distribution, in contrast to the Weibull, may more appropriately describe the measured strength data. Further investigations on strength data of $\mathrm{ZnO}$ nanowires, carbon nano-tubes and carbon nano-wires have also shown that, due to the collective interaction of flaws, an optimal strength distribution might be log-normal [16]. Although many studies have been conducted on strength distributions of advanced ceramics, there is very limited research on dental ceramics. In a recent work, Le and Bazant indicated that the introduction of a new theory based on atomistic fracture mechanics may provide more realistic predictions of the strength distribution of restorative dental ceramics [17].

In this paper, ten strength data sets of dental ceramics are fitted by three versatile distribution (i.e., Weibull, normal and log-normal) functions. In each main category, at least one data set is used. Based on the minimum information criterion and the Anderson-Darling test, the most suitable fitting distribution for categories with a special composition is 
determined. The deviations from the Weibull distribution and their possible reasons are discussed.

\section{Strength data of dental ceramics}

For convenience, dental ceramics are categorized according to their compositions. The strength data sets of ten dental ceramics were collected (see Table 1), including their specific names, the category, test methods and the source of data [18-22]. The details of categories of these dental ceramics are as follows:

(1) Category I: Materials contain silica with various amounts of alumina. Aluminosilicates in nature, which are composed of potassium and sodium, are known as feldspars. These materials can be developed into very fine grain machinable blocks, such as Vitablocs Mark II.

(2) Category II: Materials contain a high rate of silica with different crystalline fillers (leucite, lithium disilicate, etc.). According to the type of fillers and their rates, this category is divided into four subgroups: Subcategory $\mathrm{II}_{1}$ : Materials contain low-to-moderate leucitecontaining feldspathic glass called "feldspars". VM 13 and Vita are two typical examples. Subcategory $\mathrm{II}_{2}$ : Materials contain high leucite (approximately $50 \mathrm{wt}$. \%). The most widely used one is the original IPS Empress ${ }^{\circledR}$. Subcategory $\mathrm{II}_{3}$ : This contains lithium-disilicate glass ceramics (IPS Empress ${ }^{\circledR}$ II). Porcelain veneering materials for lithium-disilicate glass ceramics are also alumino-silicate glasses that contain fluoroapatite crystals rather than leucite. Subcategory $\mathrm{II}_{4}$ : Fluoromica glass ceramics (DICOR) belong to this subcategory. The mica crystals formed in DICOR are based on compositions of $\mathrm{SiO}_{2}, \mathrm{~K}_{2} \mathrm{O}, \mathrm{MgO}, \mathrm{Al}_{2} \mathrm{O}_{3}$, and $\mathrm{ZrO}_{2}$, and fluorides are added to the mixture to help produce a degree of fluorescence in the finished prosthesis. For this reason, the formulation is called a fluoromica glass ceramic. 
(3) Category III: Crystalline-based systems (mainly alumina) with glass fillers belong to this category. In-Ceram (glass-infiltrated, partially sintered alumina) is one of the most important samples.

(4) Category IV: These contain polycrystalline solids (alumina, zirconia etc.) that are formed by directly sintering crystals without any intervening matrix to form a dense, air-free, glass-free, polycrystalline structure.

\section{Statistical analysis}

\subsection{Distribution functions}

In mechanical design of advanced ceramic structures, one must ensure an extremely low failure probability such as $10^{-6}$. For such a low failure probability, it is difficult and even impossible to determine the tail of a probability density function (pdf) directly by experimental tests. Therefore, a statistical model is usually used for the determination of a pdf tail indirectly. Choosing a correct or best-fitting distribution for a given set of strength data is an important issue, especially when the tail probability, which is sensitive to the assumed model, is of interest. In this paper, three versatile functions are used such as the Weibull, normal and log-normal distributions.

The Weibull distribution is one of the most widely used lifetime distributions in design of ceramic restorations. It is a distribution that can take on the characteristics of other types of distributions, based on the shape parameter. The simplest form of a Weibull function can be written as $[13,14]$

$P(\sigma, V)=1-\exp \left[-\frac{V}{V_{0}}\left(\frac{\sigma}{\sigma_{0}}\right)^{m}\right]$

where $P(\sigma, V)$ is the cumulative failure probability of a ceramic component due to flaws, $V$ is the volume of the component, $V_{0}$ is the unit volume, $\sigma$ is the uniaxial applied stress, $m$ is the 
Weibull modulus which describes the scatter of strength, and $\sigma_{0}$ is the characteristic stress at which the failure probability is $63.2 \%$ for a specimen with $V=V_{0}$. For a set of nominally identical samples (i.e., $V=V_{0}$ ), the cumulative failure probability is

$P(\sigma)=1-\exp \left[-\left(\frac{\sigma}{\sigma_{0}}\right)^{m}\right]$

and its pdf is

$$
p(\sigma)=\frac{m}{\sigma_{0}}\left(\frac{\sigma}{\sigma_{0}}\right)^{m-1} \exp \left[-\left(\frac{\sigma}{\sigma_{0}}\right)^{m}\right]
$$

By maximizing its log-likelihood function, the two unknown parameters in the Weibull distribution are given as

$\sigma_{0}=\left\{\frac{1}{n} \sum_{i=1}^{n} \sigma_{i}^{m}\right\}^{1 / m}$ and $\frac{1}{m}=\frac{\sum_{i=1}^{n}\left[\sigma_{i}^{m} \ln \left(\sigma_{i}\right)\right]}{\sum_{i=1}^{n} \sigma_{i}^{m}}-\frac{1}{n} \sum_{i=1}^{n} \ln \left(\sigma_{i}\right)$

where $\sigma_{i}$ is strength of the $i$-th sample and $n$ is the number of samples or tests.

The strength distribution of a brittle material without surface preparation may be symmetrical and therefore the normal distribution is a potential distribution to fit its strength data [23]. The pdf of a normal distribution can be represented as

$p(\sigma)=\frac{1}{\sqrt{2 \pi \alpha}} \exp \left[-\frac{(\sigma-\bar{\sigma})^{2}}{2 \alpha^{2}}\right]$

where $\bar{\sigma}$ and $\alpha^{2}$ are the mean and variance, respectively. Their maximum likelihood estimators are

$\bar{\sigma}=\frac{1}{n} \sum_{i=1}^{n} \sigma_{i} \quad$ and $\quad \alpha^{2}=\frac{1}{n} \sum_{i=1}^{n}\left(\sigma_{i}-\bar{\sigma}\right)^{2}$

The log-normal distribution is a distribution of a random variable whose logarithm is normally distributed. Thus, its pdf can be written as 
$p(\sigma)=\frac{1}{\alpha \sigma \sqrt{2 \pi}} \exp \left[-\frac{(\ln \sigma-\bar{\sigma})^{2}}{2 \alpha^{2}}\right]$

where the mean of a log-normal distribution is $\exp \left(\bar{\sigma}+\alpha^{2} / 2\right)$ and the variance is $\exp \left(2 \bar{\sigma}+\alpha^{2}\right)\left\lfloor\exp \left(\alpha^{2}\right)-1\right]$. For maximum likelihood estimators, the same procedure as the normal distribution can be used.

\subsection{Akaike information criterion}

The $\chi^{2}$ test is one of the strongest goodness-of-fit indices, by which an appropriate strength distribution can be identified. However, in the case of small sample sizes, it is difficult to distinguish between two distributions. Therefore, the Akaike information criterion (AIC) is used, which is based on the similar consideration as the log-likelihood ratio and is a more promising method to obtain the confidence bounds. The AIC measures the goodness-offit of an estimated statistical model by linking the likelihood to a distance between true (experimental) and assumed distributions [24]. The AIC index which has been used in a number of areas as an aid to select between competing models is defined as

$$
A I C=-2 \ln \hat{L}+2 k
$$

where $k$ is the number of parameters to be fitted (for example, $k=2$ for a two-parameter

Weibull distribution), $\ln \hat{L}$ is the maximized log-likelihood for a given model and can be calculated by

$$
\ln L=\sum_{i=1}^{n} \ln f\left(Y_{i}\right)
$$

where $n$ is the number of data and $f\left(Y_{\mathrm{i}}\right)$ is the pdf of an estimated distribution. The $A I C$ values can be directly compared, preferring the distribution which gives the smallest value. In typical cases, the difference in $A I C$ values of at least 1.5 to 2 , i.e., $\triangle A I C>1.5-2$, corresponds to a reliable indication that one distribution is superior to another [24-26]. 


\subsection{Anderson-Darling test}

The Anderson-Darling test is used in order to decide whether a set of data comes from a population with a specific distribution. It is one of the most powerful statistical tools for detecting departures from normality [27]. The Anderson-Darling test is a modification of the Kolmogorov-Smirnov test, in which a more weight is given to the tails. The formula for the Anderson-Darling statistic $A$ of the ordered data $\left\{Y_{1}<Y_{2} \ldots<Y_{i} \ldots<Y_{n}\right\}$ is

$$
A^{2}=-n-S
$$

with

$S=\sum_{i=1}^{n} \frac{2 i-1}{n}\left[\ln F\left(Y_{i}\right)+\ln \left(1-F\left(Y_{n+1-i}\right)\right)\right]$

where $F$ is the cumulative distribution function of a specified distribution. Normally, the Anderson-Darling statistic $A$ is compared to a critical value and then it is determined whether data come from a specified distribution. In this paper, the distribution type with the smallest $A$ value is favored among the three distributions.

\section{Results and discussion}

In Table 2, the fitting parameters are listed for individual data sets by using the Weibull, normal and log-normal distributions. The sample size $n, A I C$ index and Anderson-Darling test statistic $A$ values are given in Table 3. Each data set contains at least 26 strength values. In the calculation of $A I C$, the normal distribution is used as a reference because strength cannot be negative. In Table 3 , the minus value of $\triangle A I C$ means that a log-normal distribution fits strength data better than the Weibull distribution; otherwise, it is just opposite. Based on the AIC criterion, when $\triangle A I C>2$, an optimal distribution can be identified [24-26]. According to AIC values in Table 3, for data sets $1-5$, there is no big difference between the Weibull and 
log-normal distributions. For data sets 6 and 7, the log-normal distribution fits strength data better than the Weibull distribution. For data sets 8, 9 and 10, however, the Weibull distribution gives the lowest $A I C$ values and is more suitable to fit those strength data. Based on the Anderson-Darling test, the distribution which provides the smallest $A$ value is more suitable function for the investigated strength data among other distributions [27]. Comparison of results in Table 3 shows that $A I C$ and Anderson-Darling tests give the same conclusions.

For categories $\mathrm{I}$ (feldspathic porcelain), $\mathrm{II}_{1}$ (feldspathic porcelain), and $\mathrm{II}_{2}$ (Leucitereinforced porcelain), the normal distribution is an appropriate function in fitting strength data. For tetrasilicic fluoromica glass-ceramic $\left(\mathrm{II}_{4}\right)$, the log-normal distribution provides the best fitting ability. For category III, there are two different results: log-normal is the best distribution for lanthanum-glass infiltrated alumina ceramic and Weibull is the most appropriate distribution for alumina-glass-infiltrated alumina porcelain. Finally, in the case of category IV (3 mol.\% yttria stabilized zirconia), the Weibull distribution shows the best fitting for zirconia produced by two different suppliers.

In Fig. 1, the empirical survivor functions (defined as a probability that is equal to one minus its cumulative distribution) are given for four typical data sets (1, 6, 7 and 10), each from one of four categories, fitted by the Weibull, normal and log-normal distributions. For data sets 1, 6 and 7, the Weibull distribution fits strength data worse than other two functions (see Fig. 1(a-c)). However, Fig. 1(d) presents a noticeable success of the Weibull distribution in fitting strength data.

Results show that the most favorable distribution for feldspathic porcelain is the normal distribution function. For data sets 1, 2 and 4, a high rate of deviation from the Weibull distribution was observed. There are two important prerequisites for the occurrence of a Weibull distribution: (i) The structure fails if one single flaw becomes critical (weakest link 
hypothesis) and (ii) dangerous flaws do not interact. A negligible interaction between flaws is only possible if the flaw density is low. Thus in most cases, the Weibull theory does not apply to porous materials. Feldspathic porcelains (e.g., Vitablocs II, Vitadur-alpha dentin, Deguceram Gold, Vita WMK 68) are porous materials, in which pore or grain is covered by small cracks. In Fig. 2, the clusters of leucite (B) around the glass matrix (A) are shown for leucite-based feldspathic porcelain. The cracks around the leucite clusters are observed. A group of pores as well as their interaction would affect the final fracture rather than only the largest one as the weakest-link model (or the Weibull distribution) postulated [29]. The size effect is a natural consequence of the Weibull distribution and by checking the existence of size effect, it can be determined whether a data set is Weibull distributed or not. If a pore diameter is large compared to the grain size, action of the pore is to triple an applied stress; otherwise, it has no influence on strength [30]. Under these conditions, strength depends on the sizes of a crack in front of the pore and its surrounding grains. As a result, the size effect on strength disappears. If the size of a pore is less than grains, existence of pores in ceramics causes multiple flaw populations. In general, ceramic components fail due to surface flaws [4, 5]; however, as the number and size of pores increase, the failure probability due to volume flaws also increases. If failure occurs due to only surface flaws (microcracks) or only volume flaws (pores), then either the surface flaw or pore size distribution will govern the strength distribution. However, if some specimens fail due to surface flaws and others fail due to volume flaws, it is then obvious that each individual flaw population (i.e., volume or surface flaws) will have its typical size distribution and lead to distributions with different Weibull parameters. As a result, the strength distribution resulting from different flaw populations will overlap and it cannot be modeled by one single flaw size distribution tail. In the case of two flaw types, the failure probability for a given stress can be defined as failure caused by flaw type I (volume flaws) and flaw type II (surface flaws) [31], respectively, that is 
$P=1-\exp \left[-\left(\frac{\sigma}{\sigma_{01}}\right)^{m_{1}}-\left(\frac{\sigma}{\sigma_{02}}\right)^{m_{2}}\right]$

where $\sigma_{01}, m_{1}$ and $\sigma_{02}, m_{2}$ are the Weibull parameters of two distributions. Orlovskaja et al. [32] performed bending tests with 100 specimens of recrystallized siliconcarbide, a porous material, and investigated the bimodality of strength distributions due to high rate of pores. In Fig. 3, the Weibull plot of measured strength values is represented [32]. It is seen that two distributions with different Weibull parameters are obtained. Moreover, Vieira and Monteiro [33] investigated the strength distribution of typical porcelain, fired at $1180 \mathrm{C}^{\circ}$ and composed of the mixture of plastic kaolinitic clay with feldspar, quartz, kaolin and talc, and they observed two groups of points with different slopes due to a bimodal flaw distribution. Thus, the strength prediction of a specimen, which fails due to volume flaws, would lead to wrong results by using strength data of specimens which fail due to surface flaws.

In Fig. 4(a-b), typical Weibull plots of data set 1 (Vitablocs Mark II) and data set 3 (Deguceram Gold) are shown, respectively. For Vitablocs Mark II, similar to recrystallized siliconcarbide in Fig. 3, it is evident that there are two different types of Weibull distributions (see Fig. 4(a)). As shown in Fig. 4(b), a kink occurs in the linear Weibull plot due to the bimodal distribution of cracks, which has to be fitted by a bimodal distribution [13]. For high strength values (fracture due to pores), strength data obey the Weibull distribution, however, for small strength values (fracture due to surface flaws), strength data deviate from the Weibull function. That is, it is bi- and multi-modal flaw size distributions that cause the deviation of strength data from the Weibull distribution.

The principal difference between normal and Weibull distributions can be appreciated in the predicted lower-bound response at the tail of a distribution. If measured strength data do not follow the Weibull distribution, extrapolating towards low strength values by the fitted distribution may result in wrong estimates for the lower tail of strength, which is of 
significance in estimating the failure probability of ceramic structures. Similarly, predicting the failure probability of a dental ceramic, whose strength is normally distributed, with a Weibull distribution may result in lower or larger values than that predicted with the normal distribution. If the Weibull distribution gives a lower failure probability than the normal distribution, an unexpected failure may occur at lower stress levels. In the opposite case, additional material has to be used to provide a larger size, which causes an expensive and larger end-product. For example, for a Vitablocs Mark II (data set 1) specimen with a unit volume, the failure probability under the maximum tensile stress of $75 \mathrm{MPa}$ is $5.2 \times 10^{-6}$ according to the normal distribution function, and $1.8 \times 10^{-3}$ according to the Weibull distribution function. Using the Weibull distribution is safer in this case because it gives a higher failure probability. However, in order to be in the reliable region, according to the Weibull distribution, the failure probability has to be decreased. This can be achieved either by decreasing the maximum tensile stress or by increasing the volume of ceramic restoration. Whereas strength is normally distributed and, according to the normal distribution, the specimen is in the reliable region. This shows the importance of determination of a best fitting function for strength data of dental ceramics.

Data sets $2-5$ contain different amounts of leucite $\left(\mathrm{KAlSi}_{2} \mathrm{O}_{6}\right)$ within a glass matrix [3436]. The microstructure of a leucite-containing dental porcelain (IPS Empress I) is shown in Fig. 5. The thermal expansion coefficients of glass and leucite are about $8.6 \times 10^{-6} /{ }^{\circ} \mathrm{C}$ and $25 \times 10^{-6} /{ }^{\circ} \mathrm{C}[37,38]$, respectively. Such a large difference between thermal expansion coefficients causes radial tensile and tangential compressive stresses within and around crystals. Above a critical particle size, stress created during cooling can induce microcracks circumferential to leucite particles (see Fig. 2 and Fig. 6 (a)). The probability of microcracking increases as the size of leucite particles increases because, due to the high thermal coefficient of leucite, the presence of tetragonal leucite in dental ceramics increases their 
coefficients of thermal expansion [39]. The correlation between the thermal expansion coefficient and the weight fraction of leucite is shown in Fig. 6(b) [39]. Micro-cracking results in crack bridging during crack propagation since branching of a primary crack into a greater number of secondary cracks, or simultaneous growth of many cracks, leads to an increase in fracture path, which results in an increase of fracture resistance ( $R$-curve). Here, the existence of $R$-curve is the main reason of deviation of strength distributions from the Weibull distribution.

Data set 6 (DICOR) is a mica based machinable glass-ceramic, consisting of $\mathrm{SiO}_{2}, \mathrm{~K}_{2} \mathrm{O}$, $\mathrm{MgO}$, and small amounts of $\mathrm{Al}_{2} \mathrm{O}_{3}$ and $\mathrm{ZnO}_{2}$. The machinability of DICOR glass-ceramic is made possible by the presence of a tetrasilic fluormica $\left(\mathrm{KMg}_{2.5} \mathrm{Si}_{4} \mathrm{O}_{10} \mathrm{~F}_{2}\right)$ as a major crystalline phase. Fluorides are added to the mixture to help produce the degree of fluorescence in the finished prosthesis. During sintering, needle-like (rod-like) crystals occur at random angles rather than plate-like crystals. The grains of DICOR are characterized by elongated rod-like structures with various sizes depending on whether the material is fine, medium or coarse grained. According to the characteristic strength, the investigated DICOR is a coarse-grained material [40], which contains rod-like grains in a residual glassy phase. Crack propagation is not likely to occur across the crystals and is more probable along the glass matrix [41]. If a crack, whenever nucleated, takes a tortuous path through the glass ceramic, more energy will be absorbed in surface production, and fracture toughness can be improved. The residual glass phase is of major importance because stress developed at the interface between crystal and glass will, to a large extent, determine the crack path. This has the advantage of forming an interlocking matrix that gives added flexural strength to the ceramic body. In DICOR, there are two different failure modes, brittle and quasi-plastic modes, which are driven by shear stress $[42,43]$. In coarse-grained glass ceramics, the occurrence of quasi-plastic mode is high due to a high partition of residual glassy phase [44]. 
This quasi-plastic behavior is the main reason for the deviation of strength data of DICOR from the Weibull distribution.

In In-Ceram systems, the alumina slip casting technique is used to form an open-pore microstructure. Since the melting point of alumina is too high to produce full densification, a porous structure is obtained. Then, the porous structure is infiltrated with lanthanum glass that has a low viscosity at high temperatures, so that the molten glass is able to penetrate into pores and results in a dense ceramic (see Fig. 7(a)) [34]. The alumina particles act as crack stoppers. As shown in Fig. 7(b), the crack propagation path in In-Ceram is presented [45], where the arrow indicates the direction of a crack. Here, the possible toughnening mechanisms include the pull-out of grains (A), bridging (B), and crack deflection (C). The crack propagates through (transgranular) and/or around (intergranular) alumina grains, generating asymmetric cracks and longer cracking paths and dissipating a more amount of energy. The energy dissipation with the crack propagation results in an $R$-curve behavior and causes a deviation from the Weibull distribution [46, 47].

Based on linear elastic fracture mechanics, the stress intensity factor increases with increasing the applied load until a critical value of $K_{\mathrm{I}}$ is reached, at which a crack is still in equilibrium and above which the unstable crack propagation takes place. Such a critical value is called as fracture toughness $K_{\mathrm{IC}}$. When there is an $R$-curve effect due to toughening, the crack growth resistance increases with crack extension [48]. In other words, the stable crack propagation occurs before an unstable failure. The crack propagation behavior is no more characterized by a single value $K_{\mathrm{IC}}$ but with $K_{\mathrm{IR}}$, which increases from $K_{\mathrm{I} 0}$, an onset value of crack growth (crack-tip toughness). As a result, failure occurs when the following conditions are satisfied [31].

$$
K_{I}=K_{I R} \quad \text { and }\left.\quad \frac{\partial K_{I}}{\partial a}\right|_{\sigma=\mathrm{const}}=\frac{d K_{I R}}{d a}
$$


In Fig. 8 (a-b), the experimentally measured fracture toughness (resistance) $K_{\mathrm{IR}}$ of leucitereinforced porcelain and In-Ceram Alumina is given as a function of crack extension $\Delta a$, respectively. As crack propagates, fracture toughness (resistance) increases, which is the indication of $R$-curve behavior.

In the existence of short (small) cracks in a material with $R$-curve, the applied stress intensity factor reaches $K_{\mathrm{I} 0}$ and the unstable crack propagation occurs since the condition $K_{\mathrm{I}}>$ $K_{\mathrm{I} 0}$ is always fulfilled. As a result, there is no stable crack propagation [31]. When a long crack exists in a material, no crack propagation occurs for the lowest load case, as shown in Fig. 8(b). However, as the condition $K_{\mathrm{I}}=K_{\mathrm{I} 0}$ is satisfied, the crack starts to propagate in a stable manner. The unstable crack propagation occurs at a $K_{\mathrm{I}}$ value more than $K_{\mathrm{I} 0}$ after the stable crack growth [31]. Therefore, it is obvious that the $R$-curve effect influences the strength of components with large cracks, but has no important effect on specimens with small defects.

The $R$-curve can be described as

$$
K_{I R}=C\left(a-a_{i}\right)^{n}
$$

where $C$ and $n$ are the fitting parameters and $n$ represents the steepness of $R$-curve and takes values of $n<0.5$. The increasing crack growth resistance leads to an increase in the Weibull modulus $m$, which can be formulized as [31]

$$
m^{*}=\frac{m}{1-2 n}
$$

where $m^{*}$ is the Weibull modulus of a material with the $R$-curve effect. According to these foundations, it can be concluded that, if a series of strength measurements are performed, specimens with large cracks (low strength) have a higher Weibull modulus than that with small cracks (high strength). Therefore, in a Weibull plot, the slope decreases as the measured strength value increases. In Fig. 9 (a-b), Weibull plots of measured strengths of IPS Empress 
and In-Ceram are shown, respectively. The dashed lines indicate the original population and solid lines show the effect of toughening mechanism due to $R$-curve behavior. For low strength data (failure due to large cracks), the Weibull modulus is higher than that for the high strength data (failure due to small cracks).

Another important aspect of critical cracks in dental ceramics is related to the slow and stable crack growth $(\mathrm{SCG}) . \mathrm{SCG}$ is a crack propagation process at stress intensity factor $\left(K_{\mathrm{I}}\right)$ level lower than the critical stress intensity factor $\left(K_{\mathrm{IC}}\right)$. Long-term and repetitive low-level loading may cause pre-existing subcritical flaws to slowly grow until failure occurs at a level of loading that is insufficient to cause unstable failure. SCG in ceramics can be characterized by the coefficient, $n$, which can be calculated using the following empirical power law

$$
v=\frac{d c}{d t}=v_{0}\left(\frac{K_{I}}{K_{I C}}\right)^{n}
$$

where $v$ is the crack velocity at an applied stress intensity factor $K_{\mathrm{I}}, c$ is the crack size, $t$ is time, $v_{0}$ is the critical velocity of the crack at the moment of fracture, and $K_{\mathrm{IC}}$ is fracture toughness. Since $K_{\mathrm{I}} / K_{\mathrm{IC}}$ is lower than 1 , as $n$ increases, the resistance to SCG and service life increase.

SCG occurs especially in the presence of water or water vapor when water molecules approach the crack tip that is under stress, resulting in a chemical reaction between water and ceramic, which breaks metal oxide bonds with subsequent production of hydroxides. Such a phenomenon eventually leads to strength degradation over time. For example, due to the heterogeneous distribution of leucite clusters in porcelain, cracks are more likely to propagate through the large areas of glassy matrix, which are more susceptible to the slow crack growth [34]. For in vitro testing, the stress rate dependence of strength is a characteristic sign of SCG [50]. In order to determine SCG, dynamic fatigue tests, in which the flexural strength of specimens is measured as a function of the crosshead speed (at different stress rates) in a 
mechanical testing machine [51]. There have been some studies, in which the SCG of dental ceramics was investigated [52-57]. For example, Cesar et al. [52] investigated the SCG of seven dental porcelains (including Vitadur Alpha) with different leucite contents and they reported that the SCG parameters of Vitadur Alpha are $n=62$ in air and $n=37$ in saliva. This shows that, saliva decreases the service life of Vitadur Alpha. Marocho et al. [53] investigated the SCG under cyclic loading of glass-infiltrated alumina-based (In-Ceram) dental ceramics and measured the SCG parameter as $n=24.76$ under wet conditions. Moreover, they observed that the crack propagation occurs at low $K_{\mathrm{I}}\left(45 \%\right.$ of $\left.K_{\mathrm{IC}}\right)$ values, which is the indication of SCG. Taskonak et al. [56] tested 150 Vitadur Alpha specimens in water at different stress rates and also in oil. They measured the median flexural strengths at stressing rates of $0.1,1$, $10,100 \mathrm{MPa} / \mathrm{s}$ as $46.9,46.5,51.0,55.3 \mathrm{MPa}$ in water and at stressing rate of $100 \mathrm{MPa} / \mathrm{s}$ as 78.4 MPa in oil. Difference between the median flexural strengths shows the existence of subcritical crack growth. In Fig. 10 (a-b), the SEM images of fracture surfaces of feldspathic porcelain [57] and IPS Empress [34] are shown, respectively. Wake hackle (WH) markings are observable on these fracture surfaces. Wake hackles form under fatigue loading when the crack tip reaches a bubble or a discontinuity, which are indicators of the direction of crack propagation.

In Fig. 11, the lifetime curves of feldspathic porcelain (VM7), IPS Empress and InCeram are given [34]. The time axis is labeled for 1 day (1d), 1 year (1y) and 10 years (10y) and the lifetime curves are extended to above 10 years in order to predict the average strength after long-life-times. The slope of the curve is related to the subcritical crack growth parameter $n$ (the lower the $n$ value, the higher the slope). The effect of SCG on the Weibull parameter $m$ was investigated by Peterlik [58]. The effect of SCG on the Weibull modulus is given as follows [58]

$m^{*}=m \frac{n+1}{n-2}$ 
where $n$ is the SCG parameter, $m$ is the Weibull modulus, and $m^{*}$ is the Weibull modulus with SCG. According to Eq. (17), it is seen that the existence of SCG increases the Weibull modulus.

It is worth noting that, in this paper, approximately 30 strength data have been used for each material in the comparison of different distribution functions. The deviations from the Weibull distribution may also be due to the low sample size. Danzer et al. [13] suggested using more than 30 data in order to perform a more reliable comparison because the size of samples defines the width of the mapped flaw interval in a double logarithmic Weibull graph. A commonly used estimator that has low bias, when used with linear regression analyses, is $P_{f}$ $=(i-0.5) / n$, where $i$ is the $i^{\text {th }}$ datum and $n$ is the total number of data points. For the number of samples $n=30$, the mapped interval includes failure probabilities of $1.7 \%$ and $98.3 \%$. Trustrum and Jayatilaka [59] reported that for $n>20$, this estimator gives parameter estimates with small bias and reasonable confidence limits.

Although Danzer et al. [13] suggested using more strength data; they also reported that the kink of the Weibull line caused by $R$-Curve behavior and multimodal flaw size occurs in the specified mapped interval when the size of specimens is appropriate. Therefore, it is possible to catch the deviation from Weibull distribution by using 30 specimens if the volume of a specimen is appropriate. For example, feldspathic porcelain is a porous material and pores occur mostly due to dissolved organic additives. After the sintering process, pores with a narrow size distribution occur in the material. If the second flaw size distribution in a bimodal flaw size distribution is narrowly peaked, the corresponding features can be seen directly in the Weibull plot of 30 specimens [60]. Moreover, the kink of a Weibull line due to multimodal flaw size can be realized if the specimen has an appropriate effective volume $\left(V_{\text {eff }}\right.$ $\approx 7.5 \mathrm{~mm}^{3}$ ) [13]. The investigated Vitablocs Mark II (data set 1) specimens have dimensions of $3 \times 4 \times 45 \mathrm{~mm}^{3}$ and the strength measurements were carried out by four-point bending tests 
according to European Standard EN 843 [18]. The effective volume of Vitablocs Mark II

(data set 1) specimens is equal to $V_{\text {eff }}=11 \mathrm{~mm}^{3}$ [61]. Therefore, by using 30 specimens, it is possible to determine the deviation form the Weibull line for these specimens.

Furthermore, in practical applications, at least 30 specimens should be used according to standards and also the Weibull parameters be determined by using the strength data of 30 specimens although the distribution is not Weibull distributed. Therefore it is critical to determine the most suitable distribution function according to 30 strength data, which is the main issue of this paper. In addition, instead of increasing the number of samples, the reliability of comparison may be increased by testing specimens with different sizes or effective volumes.

\section{Conclusions}

In this paper, procedures to ascertain a more suitable distribution have been proposed and applied to strength data of ten dental ceramics. It is shown that microstructures and compositions may affect the strength distribution of dental ceramics. The effects of microstructure induced fracture behaviors (i.e., $R$-curve, SCG, and multi-modal flaw distribution) on deviations from the Weibull distribution are explained and discussed by using the experimentally measured strength data. There is no sufficient evidence that the Weibull distribution is always preferable to other distribution functions in fitting strength data of dental ceramics. As a result, the use of the Weibull distribution for the characterization of strength should be questioned and tested prior to the design of dental ceramics. Similar to strength data, the size and shape of grains and defects are equally important in determining mechanical properties of materials. 


\section{Acknowledgements}

The authors would like to acknowledge De Martin, in Zirve University, for her editorial assistance. 


\section{References}

[1] N. Kraemer, R. Frankberger, Clinical performance of bonded leucite-reinforced glass ceramic inlays and onlays after eight years, Dent. Mater. 21 (3) (2005) 262-2671.

[2] E.A. McLaren, P.T. Cao, Ceramics in dentistry-Part I: Classes of materials, Inside Dentistry 5 (9) (2009) 94-104.

[3] B.R. Lawn, Fracture of brittle solids, second ed., Cambridge University Press, Cambridge, (1993).

[4] S. Nohut, G.A. Schneider, Failure probability of ceramic coil springs, J. Eur. Ceram. Soc. 29 (6) (2009) 1013-1019.

[5] S. Nohut, A. Usbeck, H. Özcoban, D. Krause, G.A. Schneider, Determination of the multiaxial failure criteria for alumina ceramics under tension-torsion test, J. Eur. Ceram. Soc. 30 (16) (2010) 3339-3349.

[6] R. Danzer, A general strength distribution function for brittle materials, J. Eur. Ceram. Soc. 10 (6) (1992) 461-472.

[7] D.J. Green, An introduction to the mechanical properties of ceramics, Cambridge University Press, Cambridge, (1998).

[8] J.E. Ritter, Predicting lifetimes of materials and material structures, Dent. Mater. 11 (2) (1995) 142-146.

[9] W. Weibull, A statistical distribution function of wide applicability, J. Appl. Mech. 18 (2) (1951) 293-297.

[10] K. Trustrum, A.D. Jayatilaka, Applicability of Weibull analysis for brittle materials, J. Mater. Sci. 18 (9) (1983) 2765-2570.

[11] J.B. Quinn, G.D. Quinn, A practical and systematic review of Weibull statistics for reporting strengths of dental materials, Dent. Mater. 26 (2) (2010) 135-147. 
[12] R. Danzer, Some notes on the correlation between fracture and defect statistics: Are Weibull statistics valid for very small specimens?, J. Eur. Ceram. Soc. 26 (15) (2006) 3043-3049.

[13] R. Danzer, P. Supancic, J. Pascual, T. Lube, Fracture statistics of ceramics-Weibull statistics and deviations from Weibull statistics, Eng. Fract. Mech. 74 (18) (2007) 29192932.

[14] C. Lu, R. Danzer, F.D. Fischer, Fracture statistics of brittle materials: Weibull or normal distribution, Phys. Rev. E 65 (6) (2002) 067102.

[15] B. Basu, D. Tiwari, D. Kundu, R. Prasad, Is Weibull distribution the most appropriate statistical strength distribution for brittle materials?, Ceram. Int. 35 (1) (2009) 237-246.

[16] C. Lu, Fracture statistics of brittle materials at micro- and nano scales, Int. J. Mater. Res. 102 (6) (2011) 627-633.

[17] J.L. Le, Z.P. Bazant, Strength distribution of dental restorative ceramics: Finite weakest link model with zero threshold, Dent. Mater. 25 (5) (2009) 641-648.

[18] U. Lohbauer, A. Petschelt, P. Greil, Lifetime prediction of CAD/CAM dental ceramics, J. Biomed. Mater. Res. 63 (6) (2002) 780-785.

[19] O. Addison, J.P. Fleming, The influence of cement lute, thermocycling and surface preparation on the strength of a porcelain laminate veneering material, Dent. Mater. 20 (3) (2004) 286-292.

[20] Y. Nakamura, S. Hojo, H. Sato, Effects of thermal cycling and surface roughness on the Weibull distribution of porcelain strength, Dent. Mater. J. 28 (4) (2009) 433-437.

[21] J. Tinschert, R. Marx, K.J. Anusavice, Structural reliability of alumina-, feldspar-, leucite-, mica-and zirconia based ceramics, J. Dent. 28 (7) (2000) 529-535.

[22] C.J. Ho, H.C. Liu, W.H. Tuan, Effect of abrasive grinding on the strength of TZP, J. Eur. Ceram. Soc. 29 (12) (2009) 2665-2669. 
[23] R.H. Doremus, Fracture statistics: A comparison of the normal, Weibull and type I extreme value distributions, J. Appl. Phys. 54 (1) (1983) 193-199.

[24] H. Akaike, A new look at the statistical model identification, IEEE T. Automat. Cont. 19 (6) (1974) 716-723.

[25] C. Lu, Y.W. Mai, Y.G. Shen, Optimum information in cracking noise, Phys. Rev. E 72 (2) (2005) 027101.

[26] C. Lu, R. Danzer, F.D. Fischer, Influence of threshold stress on the estimation of the Weibull statistics, J. Am. Ceram. Soc. 85 (6) (2002) 1640-1642.

[27] M.A. Stephens, EDF statistics for goodness of fit and some comparisons, J. Stat. Am. Assoc. 69 (347) (1974) 730-737.

[28] A. Della Bona, Characterizing Characterizing ceramics and the interfacial adhesion to resin: I - The relationship of microstructure, composition, properties and fractography, J. Appl. Oral Sci. 13(1) (2005) 1-9.

[29] C. Lu, R. Danzer, F.D. Fischer, Scaling of fracture strength in ZnO: Effects of pore/grain-size interaction and porosity, J. Eur. Ceram. Soc. 24 (14) (2004) 3643-3651.

[30] A. Zimmermann, J. Rödel, Fracture statistics based on pore/grain-size interactions, J. Am. Ceram. Soc. 82 (8) (1999) 2279-2281.

[31] D. Munz, T. Fett, Ceramics: mechanical properties, failure behavior, materials selection, Springer Verlag, Berlin, Heidelberg, New York, (1999).

[32] N. Orlovskaja, H. Peterlik, W. Steinkellner, K. Kromp, Prediction of strength of recryztallied siliconcarbide from pore size measurement. Part I The bimodality of the distribution, J. Mater. Sci. 35 (3) (2000) 699-705.

[33] C.M.F. Vieira, S.N. Monteiro, Evaluation of a plastic clay from the state of Rio de Janeiro as a component of porcelain tile body, Materia 12(1) (2007) 1-7. 
[34] C.C. Gonzaga, P.F. Cesar, W.G. Miranda, H.N. Yoshimura, Slow crack growth and reliability of dental ceramics, Dent. Mater. 27 (4) (2011) 394-406.

[35] A. Della Bona, J.J. Mecholsky, J. Anusavice, Fracture behavior of lithia disilicate- and leucite-based ceramics, Dent. Mater. 20 (10) (2004) 956-962.

[36] I. L. Denry, J.A. Holloway, Ceramics for dental applications: A review, Mater. 3 (1) (2010) 351-368.

[37] P.J. Vergano, D.C. Hill, D.R. Uhlmann, Thermal expansion of feldspar glasses, J. Am. Ceram. Soc. 50 (1) (1967) 59-60.

[38] D. Taylor, C.M.B. Henderson, The thermal expansion of the leucite group of minerals, Am. Miner. 53 (Sept-Oct) (1968) 1476-1489.

[39] J.R. Mackert Jr., A.L. Evans, Multiple firing effect on leucite content of dental porcelains and correlation with thermal expansions, J. Dent. Res. 71 (1992) 238.

[40] D.T. Le, L. Qi, G. Zhang, S.J. Ng, Microstructural effects on the machining performance of dental ceramics, Technical Research Report, Harvard University, T.R. 97-36, (1997).

[41] I.L. Denry, Recent advances in ceramics for dentistry, Crit. Rev. Oral Biol. Med. 7(2) (1996) 134-143.

[42] J.Y. Thomson, K.J. Anusavice, A. Naman, H.E. Morris, Fracture surface characterization of clinically failed all-ceramic crowns, J. Dent. Res. 73 (12) (1994) $1824-1832$.

[43] I.M. Peterson, A. Pajares, B.R. Lawn, V.P. Thomson, E.D. Rekow, Mechanical characterization of dental ceramics by Hertzian contacts, J. Dent. Res. 77 (4) (1998) $589-602$. 
[44] B.R. Lawn, Y. Deng, I.K. Lloyd, M.N. Janal, E.D. Rekow, V.P. Thompson, Material design of ceramic-based layer structures for crowns, J. Dent. Res. 81 (6) (2002) 433 438.

[45] M. Guazzato, M. Albakry, S.P. Ringer, M.V. Swain, Strength, fracture toughness and microstructure of a selection of all-ceramic materials. Part I. Pressable and alumina glass-infiltrated ceramics, Dent. Mater. 20(5) (2004) 441-448.

[46] H. Fischer, W. Rentzsch, R. Marx, R-curve behavior of dental ceramic materials, J. Dent. Res. 81 (8) (2002) 547-551.

[47] S. Nohut, Prediction of crack-tip toughness of alumina for given residual stresses with parallel-bonded-particle model, Comp. Mater. Sci. 50 (4) (2011) 1509-1519.

[48] J. Llorca, R.W. Steinbrech, Fracture of alumina: An experimental and numerical study, J. Mater. Sci. 26 (23) (1991) 6383-6390.

[49] P.F. Cesar, V. Rosa, M.M. Pinto, H.N. Yoshimura, L.R. Xu, Effect of ion exchange on R-curve behavior of a dental porcelain, J. Mater. Sci. 46 (2011) 117-122.

[50] J.E. Ritter, Engineering design and fatigue of brittle materials, In: F.F. Lange editor, Fracture mechanics of ceramics, Plenum Press, New York, (1978), pp. 613-646.

[51] J.E. Ritter, Critique of test methods for lifetime predictions, Dent. Mater. 11(2) (1995) $147-151$

[52] P.F. Cesar, F.N. Soki, H.N. Yoshimura, C.C. Gonzaga, V. Styopkin, Influence of leucite content on slow crack growth of dental porcelains, Dent. Mater. 24 (8) (2008) 1114 1122.

[53] S.M.S. Marocho, A.R. Studart, M.A. Bottino, A. Della Bona, Mechanical strength and subcritical crack growth under wet cyclic loading of glass-infiltrated dental ceramics, Dent. Mater. 26 (5) (2010) 483-490. 
[54] R. Morena, G. M. Beaudreau, P.E. Lockwood, A.L. Evans, C.W. Fairhurst, Fatigue of dental ceramics in a simulated oral environment, J. Dent. Res. 65 (7) (1986) 993-997.

[55] C.W. Fairhurst, P.E. Lockwood, R.D. Ringle, S.W. Twiggs, Dynamic fatigue of feldspathic porcelain, Dent. Mater. 9 (4) (1993) 269-273.

[56] B. Taskonak, J.A. Griggs, J.J. Mecholsky, J.H. Yan, Analysis of subcritical crack growth in dental ceramics using fracture mechanics and fractography, Dent. Mater. 24 (5) (2008) 700-707.

[57] M. Borba, M.D. de Araujo, K.A. Fukushima, H.N. Yoshimura, P.F. Cesar, J.A. Griggs, A. Della Bona, Effect of the microstructure on the lifetime of dental ceramics, Dent. Mater. 27(7) 2011 710-721.

[58] H. Peterlik, Comparison of evaluation procedures for the subcritical crack growth parameter n, J. Eur. Ceram. Soc. 13 (1994) 509-519

[59] K. Trustrum, A.D.S. Jayatilaka, On estimating the Weibull modulus for a brittle material, J. Mater. Sci. 12 (1979) 1080-1084.

[60] R. Danzer, T. Lube, P. Supancic, Monte Carlo Simulations of Strength Distributions of Brittle Materials - Type of Distribution, Specimen and Sample Size, Z. Metallkd. 92(7) (2001) 773-783.

[61] H. Fischer, W. Rentzsch, R. Marz, A modified size effect model for brittle nonmetallic materials, Eng. Fract. Mech. 69(7) (2002) 781-791. 


\section{Figure captions}

Fig. 1. Survivor functions for data sets of (a) 1, (b) 6, (c) 7, and (d) 10 fitted by using normal, log-normal and Weibull distribution functions.

Fig. 2. Photomicrograph of a leucite-based feldspathic porcelain (Vita Omega) reproduced with permission from Ref. [28], licensed under Creative Commons Attribution License (http://creativecommons.org/licenses/by-nc/3.0/)).

Fig. 3. A Weibull plot of measured strengths of recrystallized silicon carbide [31]. The dashed line is the original population and solid lines are volume and surface flaw populations.

Fig. 4. A Weibull plot of measured strengths of (a) data set 1 and (b) data set 2. The dashed line indicates the original population and solid lines indicate volume and surface flaw populations.

Fig. 5. (A) SEM micrograph of IPS Empress I (reproduced with permission from Ref. [34]), and (B) XRD analysis showing the presence of leucite crystals in a glassy phase of IPS Empress core ceramic (reproduced with permission from Ref. [35]).

Fig. 6. (a) Defects in feldspathic porcelain, where numerals indicate (1) inclusion, (2) pore, and (3) crack (reproduced with permission from Ref. [36]). (b) Correlation between the thermal expansion coefficient and weight fraction of leucite [39].

Fig. 7. (a) SEM micrograph of In-Ceram alumina (reproduced with permission from Ref. [34]), and (b) crack propagation and toughening mechanisms in In-Ceram (reproduced with permission from [45]).

Fig. 8. Fracture toughness $K_{\mathrm{IR}}$ as a function of crack extension $\Delta a$ for (a) leucite-reinforced dental porcelain [49] and (b) In-Ceram [46]. 
Fig. 9. The Weibull plot of measured strengths of (a) data set 5 (IPS Empress) and (b) data set 7 (In-Ceram). The dashed lines indicate the original population and solid lines show the effect of toughening mechanism due to $R$-curve behavior.

Fig. 10. SEM images of fracture surfaces of (a) VM7 feldspathic porcelain (reproduced with permission from [57]) and (b) IPS Empress (reproduced with permission from [34]) with wake hackles (WH).

Fig. 11. Lifetime curves for feldspathic porcelain (VM7), IPS Empress, and In-Ceram [34]. 
Table 1

Strength data sets of ten dental ceramics, where 4PBT indicates the 4-point bending test and B3BT represents the ball-on-three-balls test [18-22].

\begin{tabular}{|c|c|c|c|c|}
\hline \multirow{2}{*}{$\begin{array}{c}\text { Data } \\
\text { set }\end{array}$} & \multirow[b]{2}{*}{ Specimen } & Test & \multirow[b]{2}{*}{ Category } & \multirow[b]{2}{*}{ Ref. } \\
\hline & & & & \\
\hline 1 & Feldspathic porcelain [Vitablocs Mark II] & 4PBT & I & {$[18]$} \\
\hline 2 & Feldspathic porcelain [Vitadur-alpha dentin] & Biaxial & $\mathrm{II}_{1}$ & [19] \\
\hline 3 & Feldspathic porcelain [Deguceram Gold] & 4PBT & $\mathrm{II}_{1}$ & [20] \\
\hline 4 & Feldspathic porcelain [Vita VMK 68] & 4PBT & $\mathrm{II}_{1}$ & {$[21]$} \\
\hline 5 & Leucite-reinforced porcelain [IPS Empress] & 4PBT & $\mathrm{II}_{2}$ & {$[21]$} \\
\hline 6 & Tetrasilicic fluoromica glass-ceramic [DICOR] & 4PBT & $\mathrm{II}_{4}$ & {$[21]$} \\
\hline 7 & Lanthanum-glass infiltrated alumina [In-Ceram] & 4PBT & III & {$[18]$} \\
\hline 8 & Alumina-glass infiltrated alumina [In-Ceram] & 4PBT & III & {$[21]$} \\
\hline 9 & 3 mol.\% yttria stabilized zirconia & 4PBT & IV & This paper \\
\hline 10 & 3 mol.\% yttria stabilized zirconia & B3BT & IV & {$[22]$} \\
\hline
\end{tabular}


Table 2

The fitted parameters by using the Weibull, normal and log-normal distributions, respectively.

\begin{tabular}{crrrrrc}
\hline & \multicolumn{2}{c}{ Weibull } & \multicolumn{2}{c}{ Normal } & \multicolumn{2}{c}{ Log-normal } \\
\cline { 2 - 7 } Data set & \multicolumn{1}{c}{$m$} & $\sigma_{0}$ & $\sigma_{\text {mean }}$ & $\sigma_{\text {dev }}$ & $\sigma_{\text {mean }}$ & $\sigma_{\text {dev }}$ \\
\hline 1 & 10.85 & 134.16 & 128.57 & 12.85 & 4.85 & 0.10 \\
2 & 6.93 & 54.19 & 50.75 & 7.99 & 3.91 & 0.16 \\
3 & 13.33 & 107.58 & 103.57 & 8.90 & 4.64 & 0.09 \\
4 & 9.99 & 87.93 & 83.90 & 9.03 & 4.42 & 0.11 \\
5 & 7.98 & 88.30 & 83.09 & 12.12 & 4.41 & 0.15 \\
6 & 5.83 & 75.80 & 70.65 & 12.01 & 4.24 & 0.17 \\
7 & 4.84 & 447.64 & 410.49 & 91.52 & 5.99 & 0.22 \\
8 & 6.03 & 464.74 & 430.33 & 85.55 & 6.04 & 0.22 \\
9 & 12.86 & 411.04 & 394.62 & 36.79 & 5.97 & 0.10 \\
\hline 10 & 27.42 & 1000.93 & 981.05 & 43.35 & 6.89 & 0.04 \\
\hline
\end{tabular}


Table 3

The AIC values calculated by using the Weibull $\left(A I C_{\mathrm{w}}\right)$, normal $\left(A I C_{\mathrm{n}}\right)$ and log-normal $\left(A I C_{\mathrm{ln}}\right)$ distributions, where $\triangle A I C=A I C_{\mathrm{ln}}-A I C_{\mathrm{w}}$. Also listed are the Anderson-Darling test statistic $(A)$ values by the three distributions.

\begin{tabular}{ccccccccc}
\hline & \multicolumn{4}{c}{ Akaike information criterion } & \multicolumn{3}{c}{ Anderson-Darling test } \\
\cline { 3 - 8 } Data set & $n$ & $A I C_{\mathrm{w}}$ & $A I C_{\mathrm{n}}$ & $A I C_{\mathrm{ln}}$ & $\Delta A I C$ & $A_{\mathrm{w}}$ & $A_{\mathrm{n}}$ & $A_{\mathrm{ln}}$ \\
\hline 1 & 29 & 235.21 & 234.28 & 236.56 & 1.35 & 1.01 & 0.86 & 0.92 \\
2 & 30 & 215.17 & 213.70 & 213.94 & -1.23 & 0.65 & 0.61 & 0.62 \\
3 & 30 & 220.20 & 220.19 & 221.27 & 1.07 & 0.53 & 0.52 & 0.59 \\
4 & 32 & 237.58 & 235.52 & 236.49 & -1.09 & 0.67 & 0.56 & 0.65 \\
5 & 32 & 253.98 & 254.35 & 255.64 & 1.66 & 0.58 & 0.57 & 0.64 \\
6 & 30 & 242.44 & 238.19 & 237.15 & -5.29 & 1.01 & 0.76 & 0.63 \\
7 & 29 & 349.36 & 348.16 & 346.65 & -2.91 & 0.72 & 0.69 & 0.62 \\
8 & 30 & 354.57 & 355.99 & 360.08 & 5.51 & 0.75 & 0.76 & 0.87 \\
9 & 26 & 264.07 & 265.18 & 266.14 & 2.07 & 0.61 & 0.67 & 0.75 \\
10 & 31 & 323.52 & 325.58 & 326.38 & 2.86 & 0.49 & 0.68 & 0.72 \\
\hline
\end{tabular}



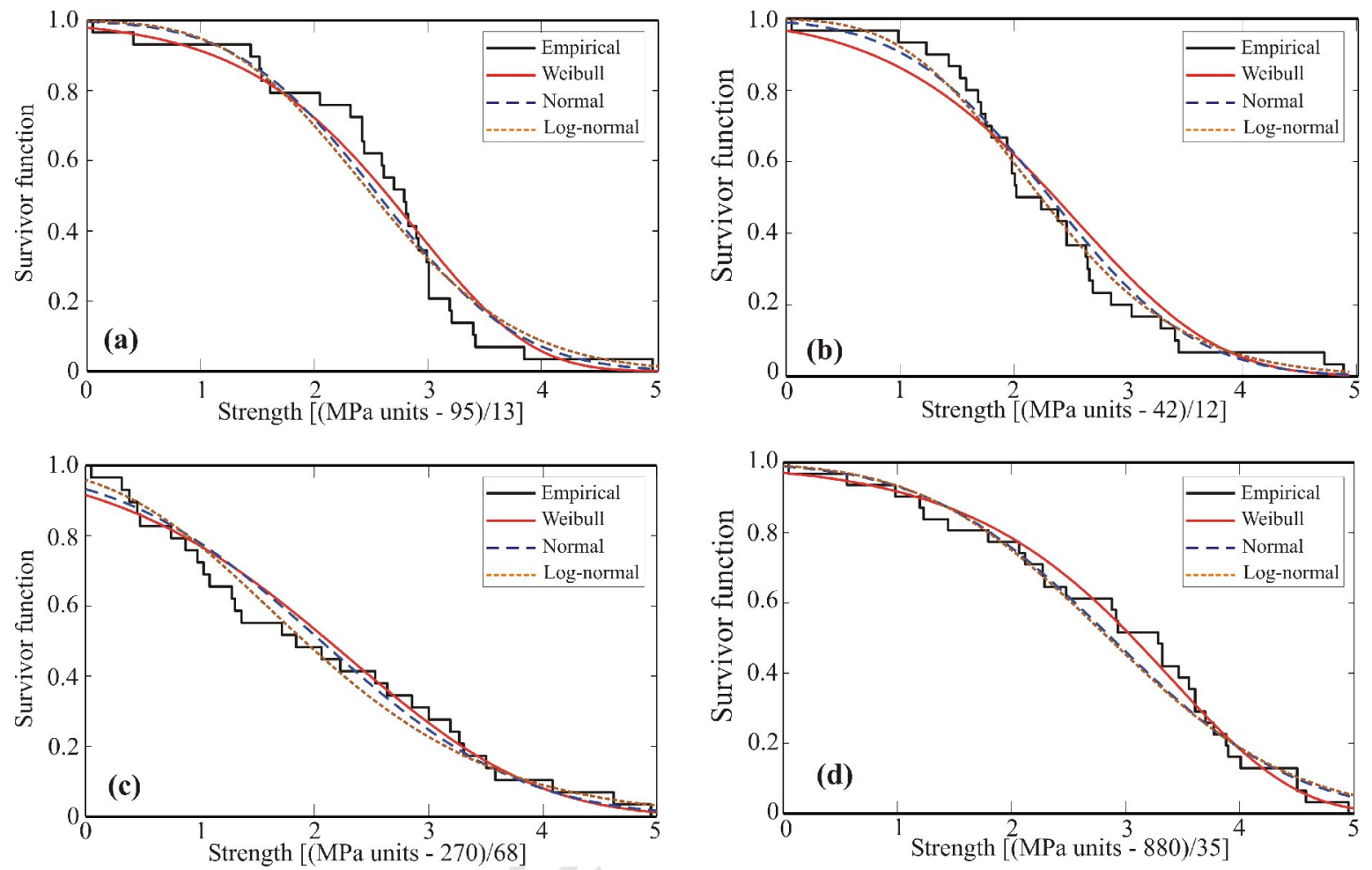

Fig. 1 


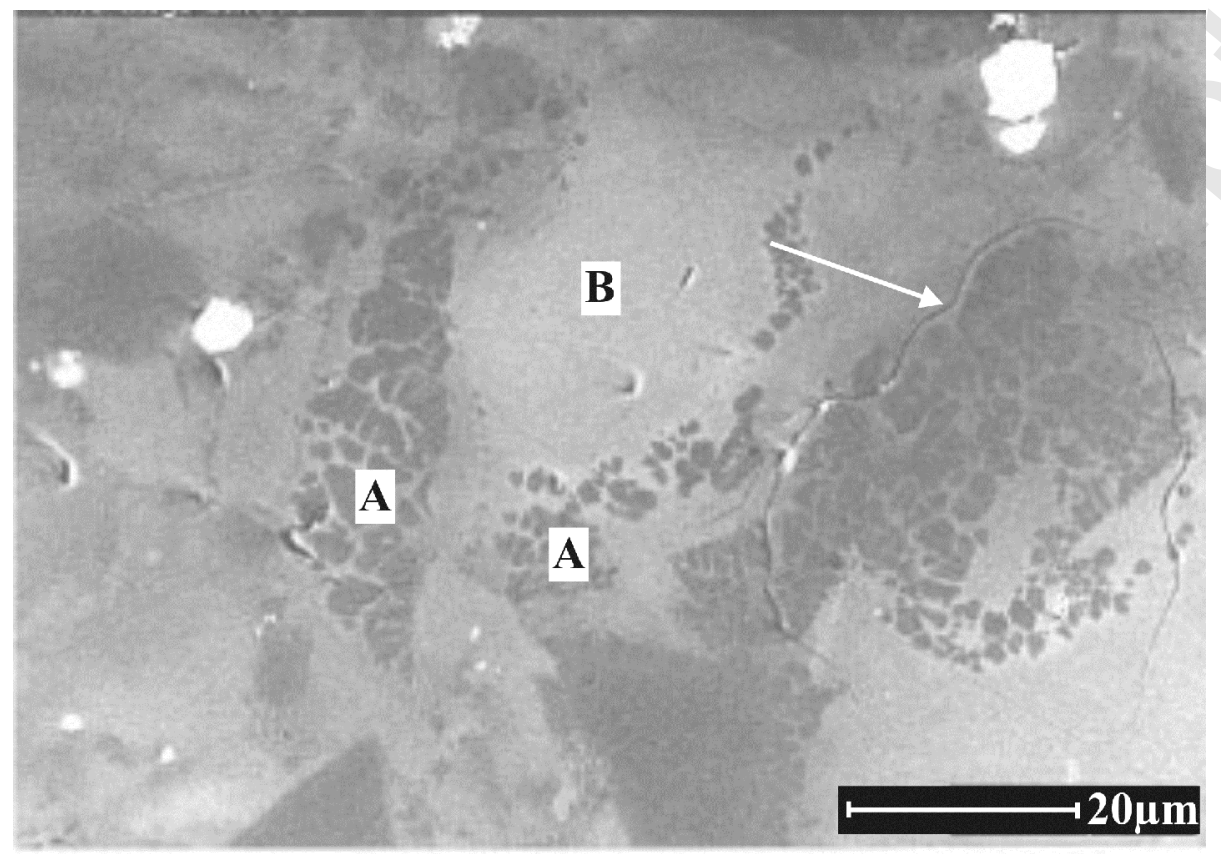

Fig. 2 


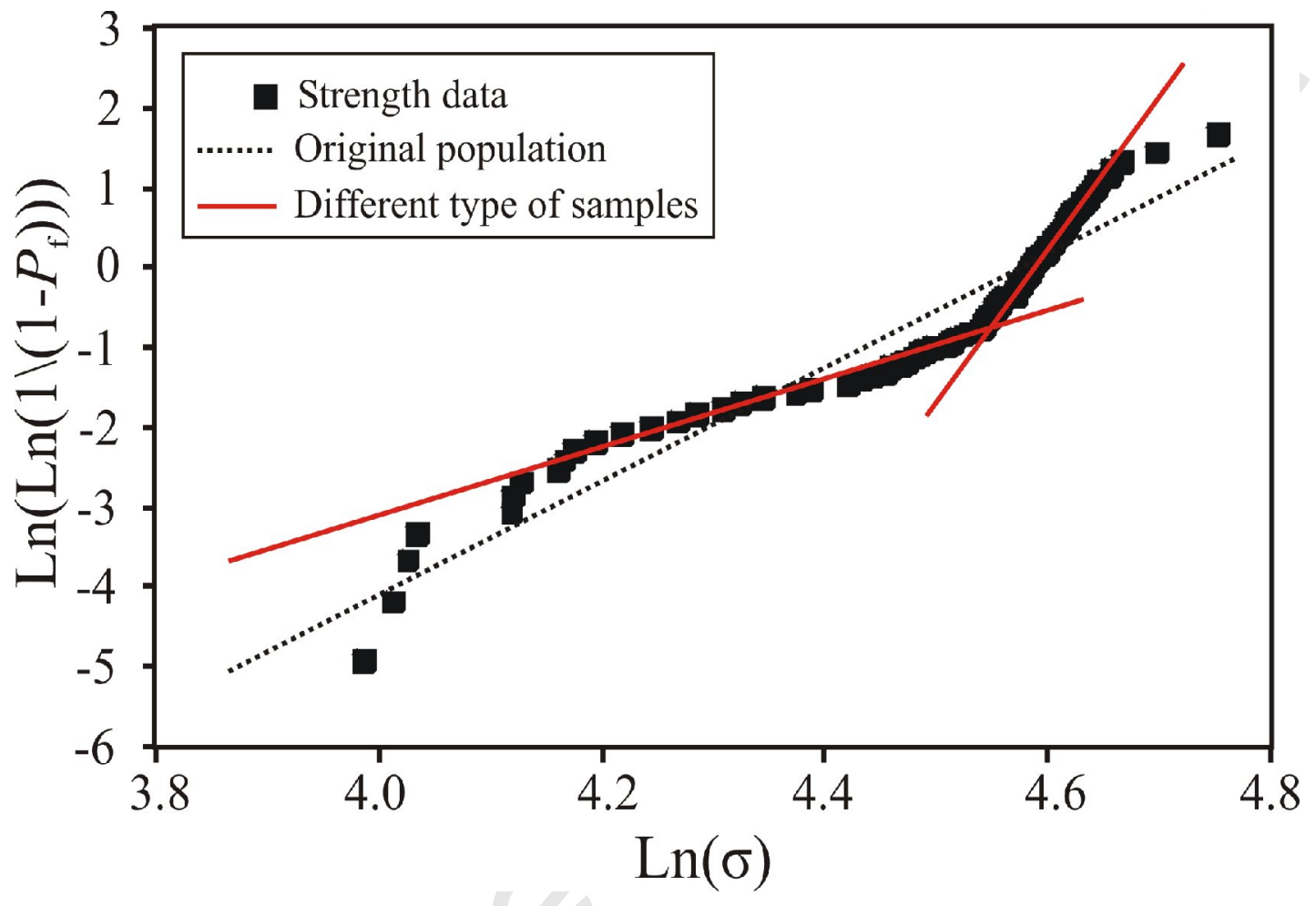

Fig. 3 

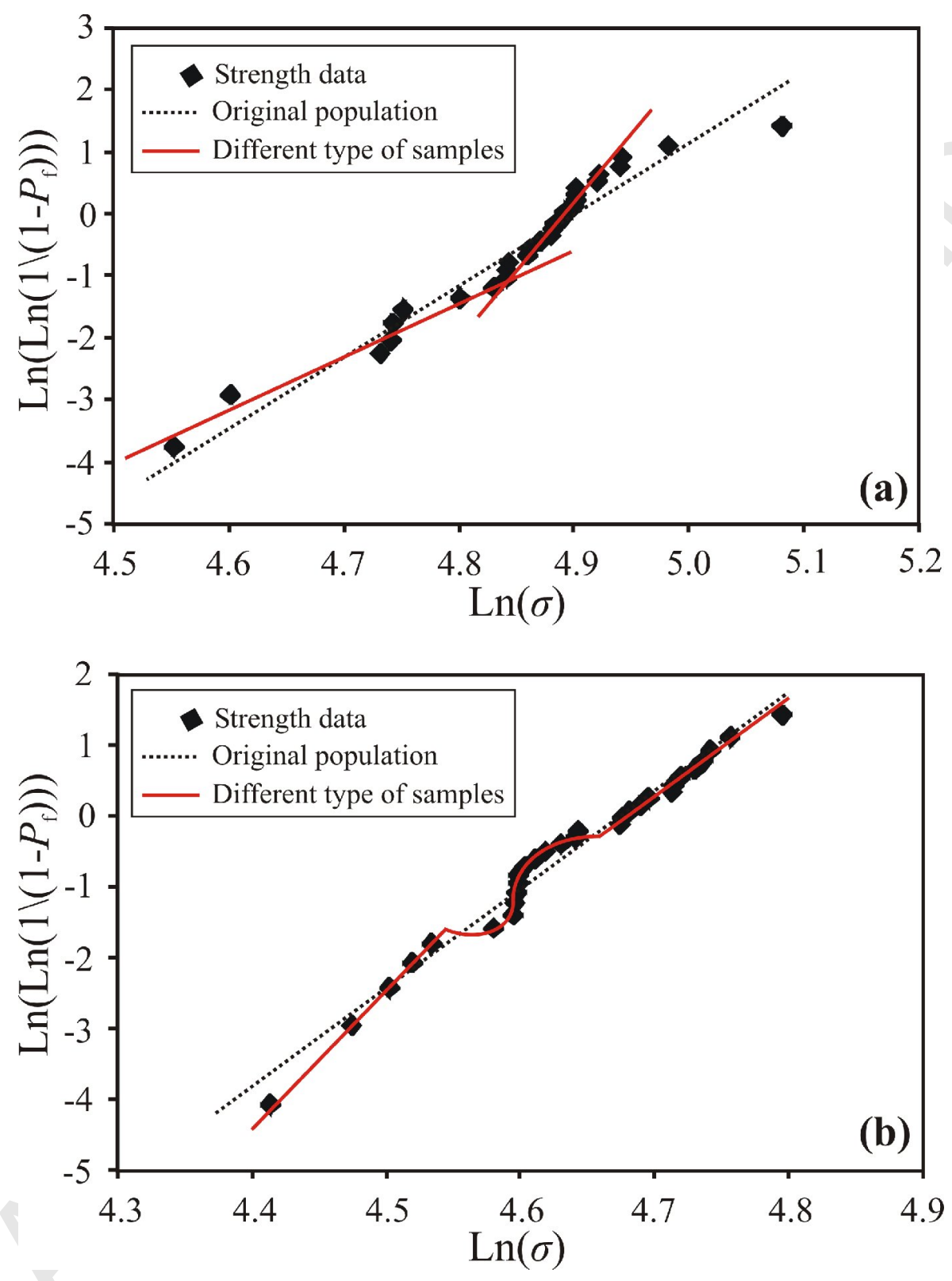

Fig. 4 

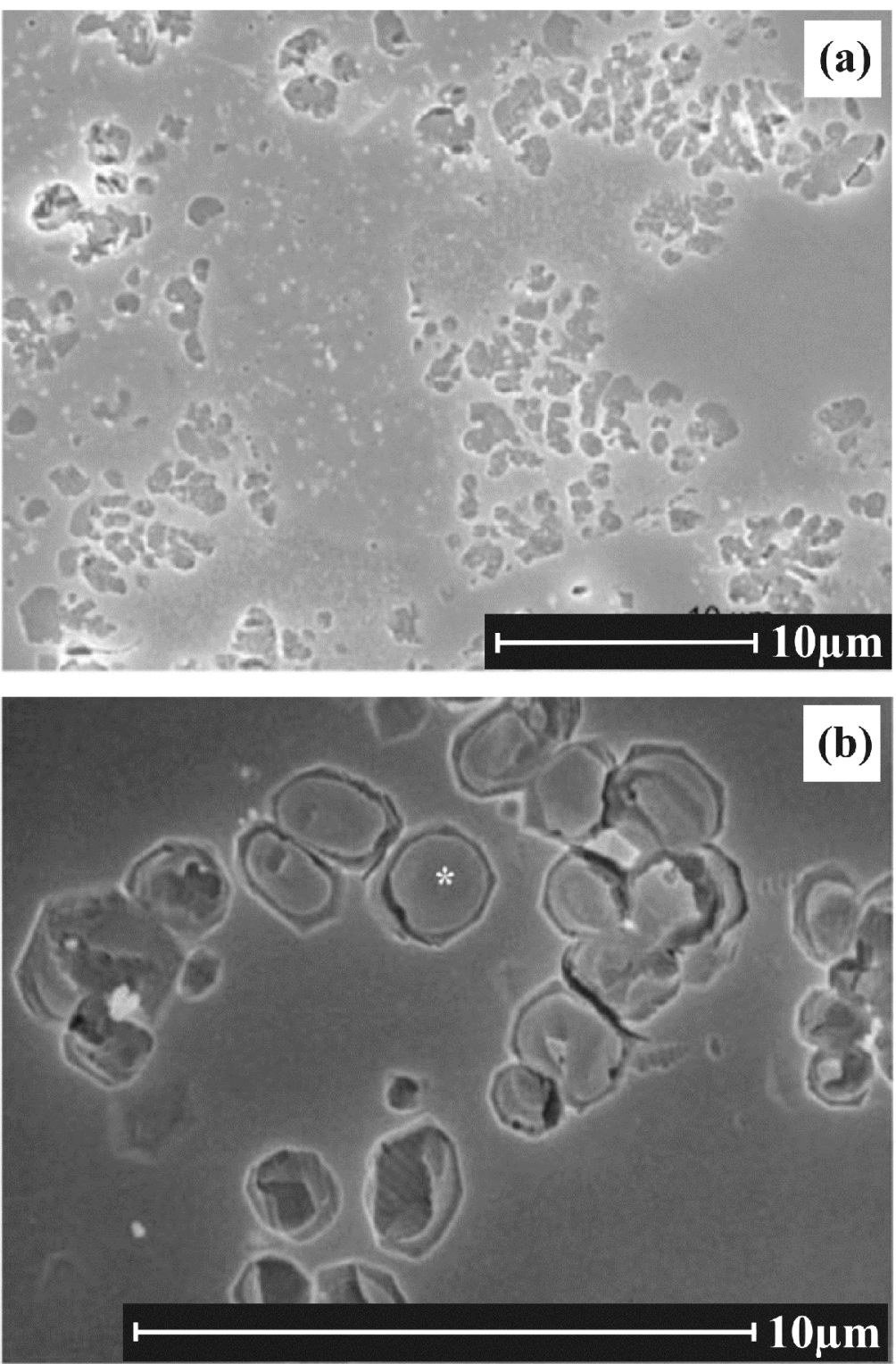

Fig. 5 

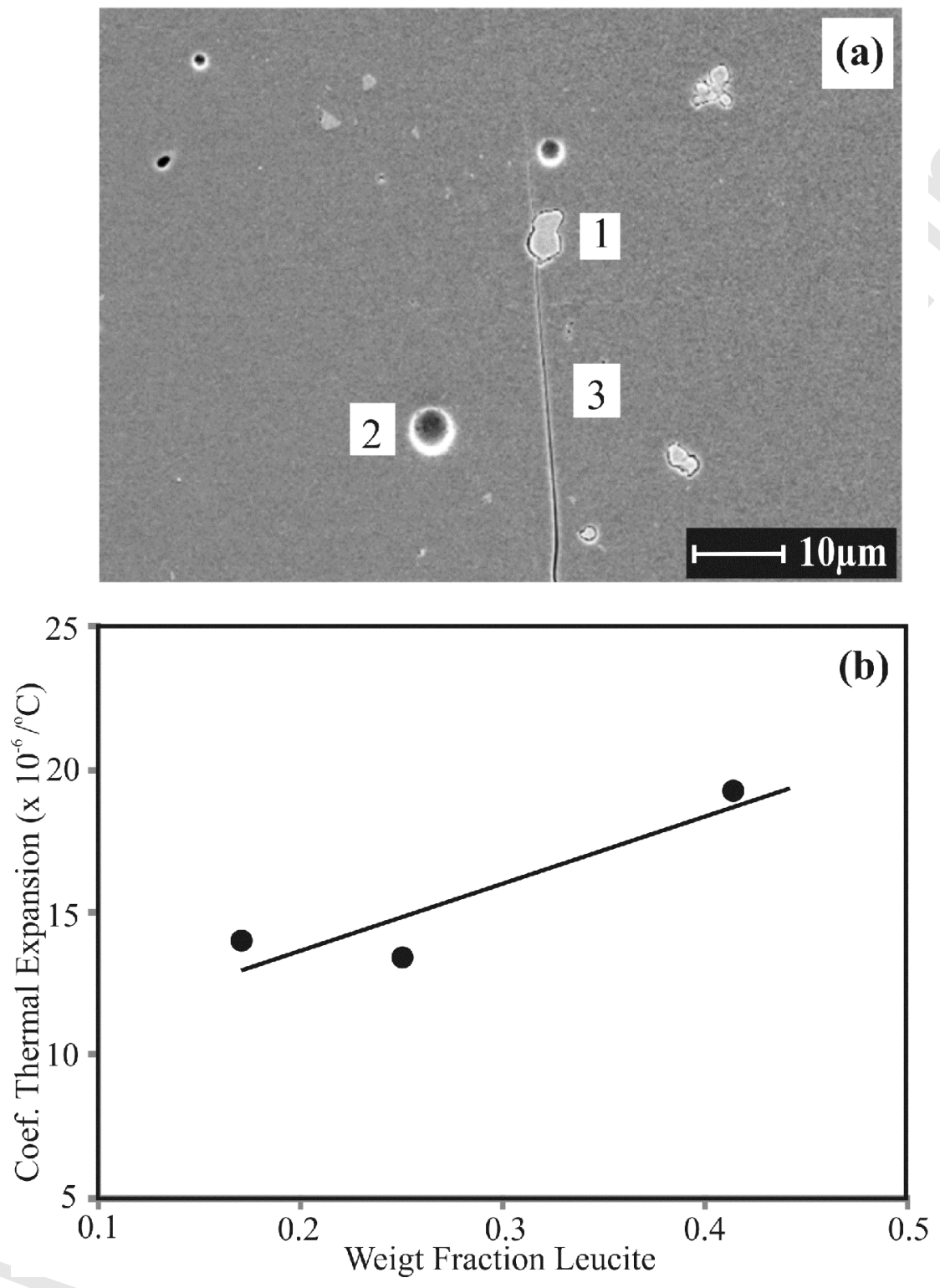

Fig. 6 

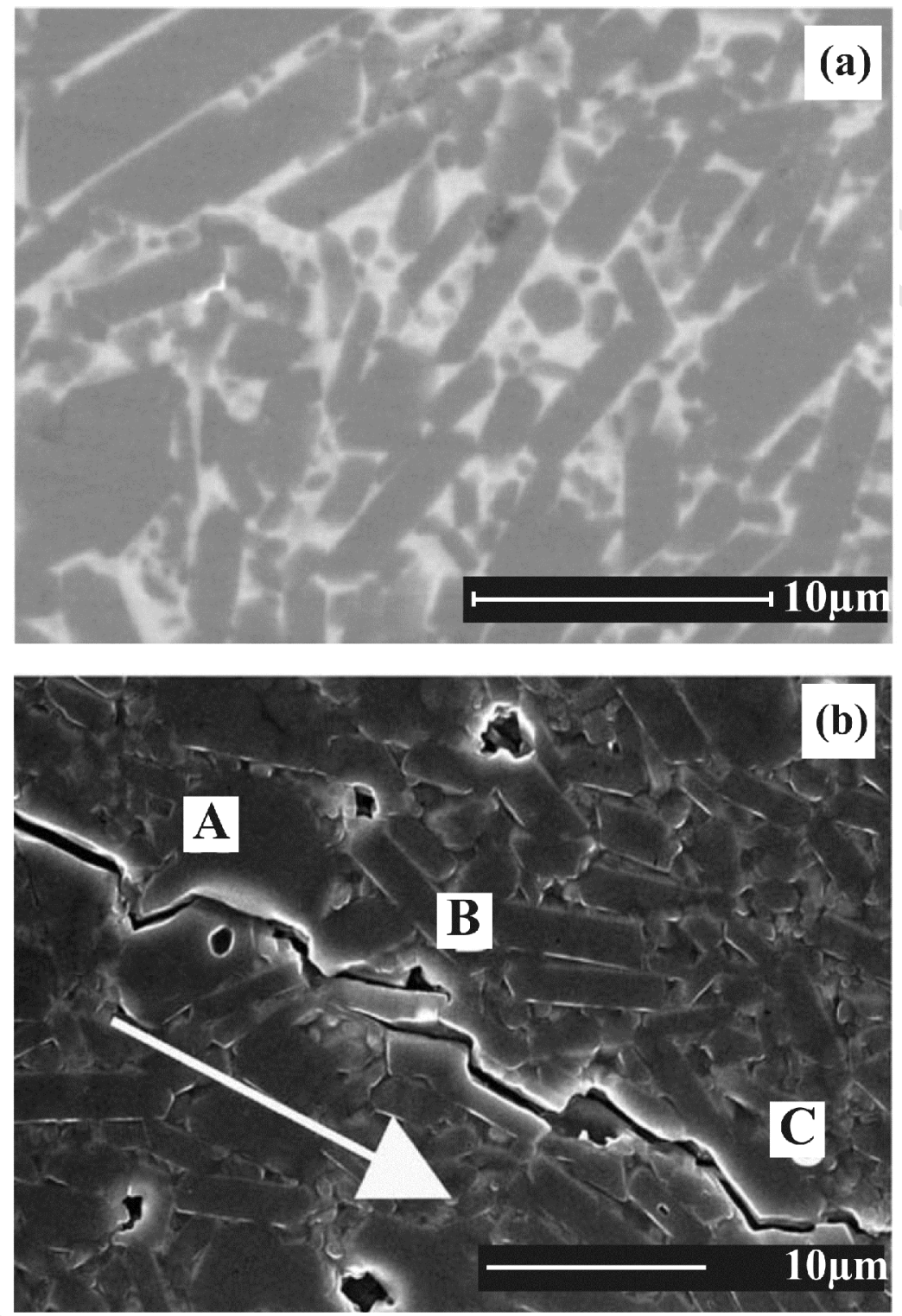

Fig. 7 

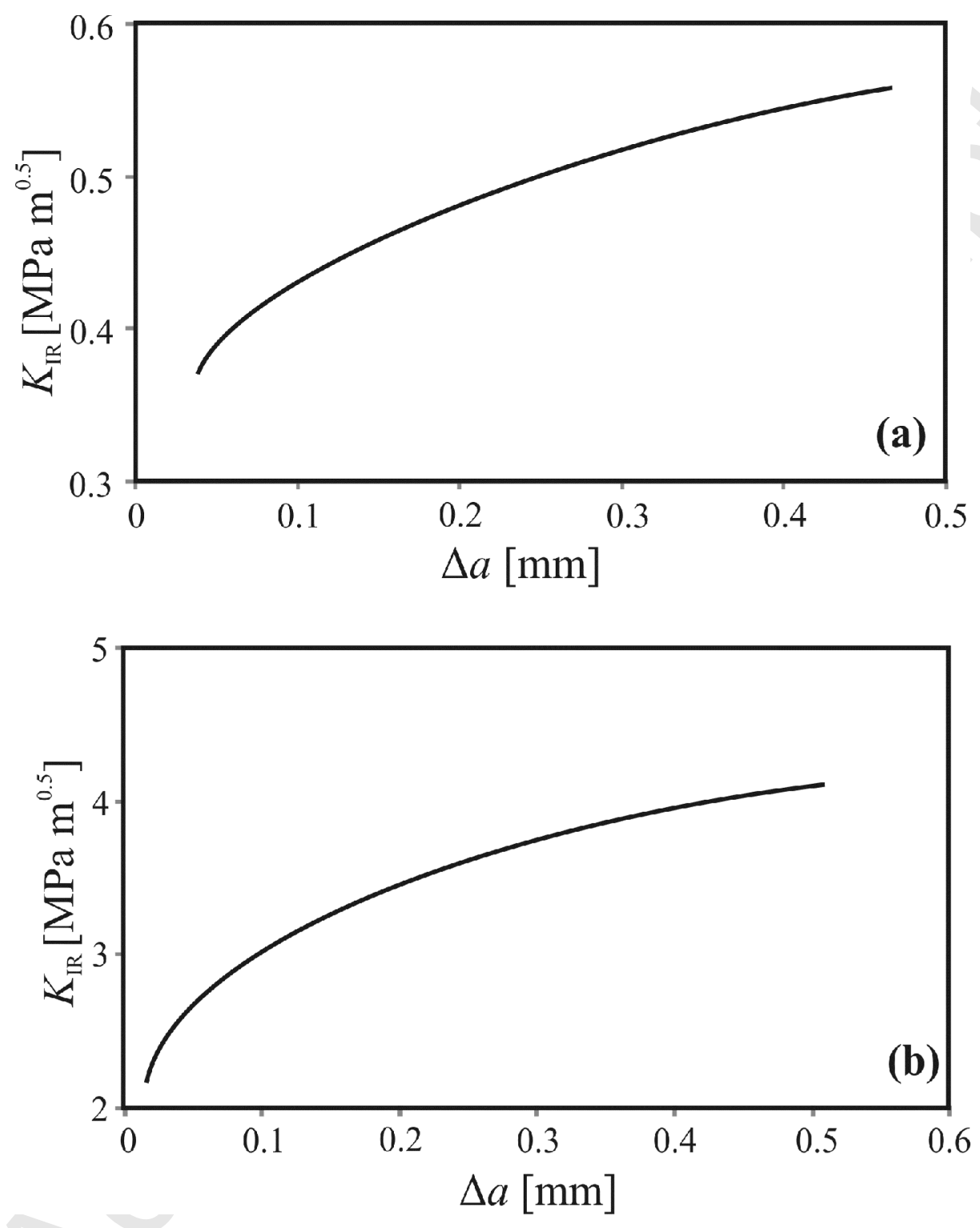

Fig. 8 

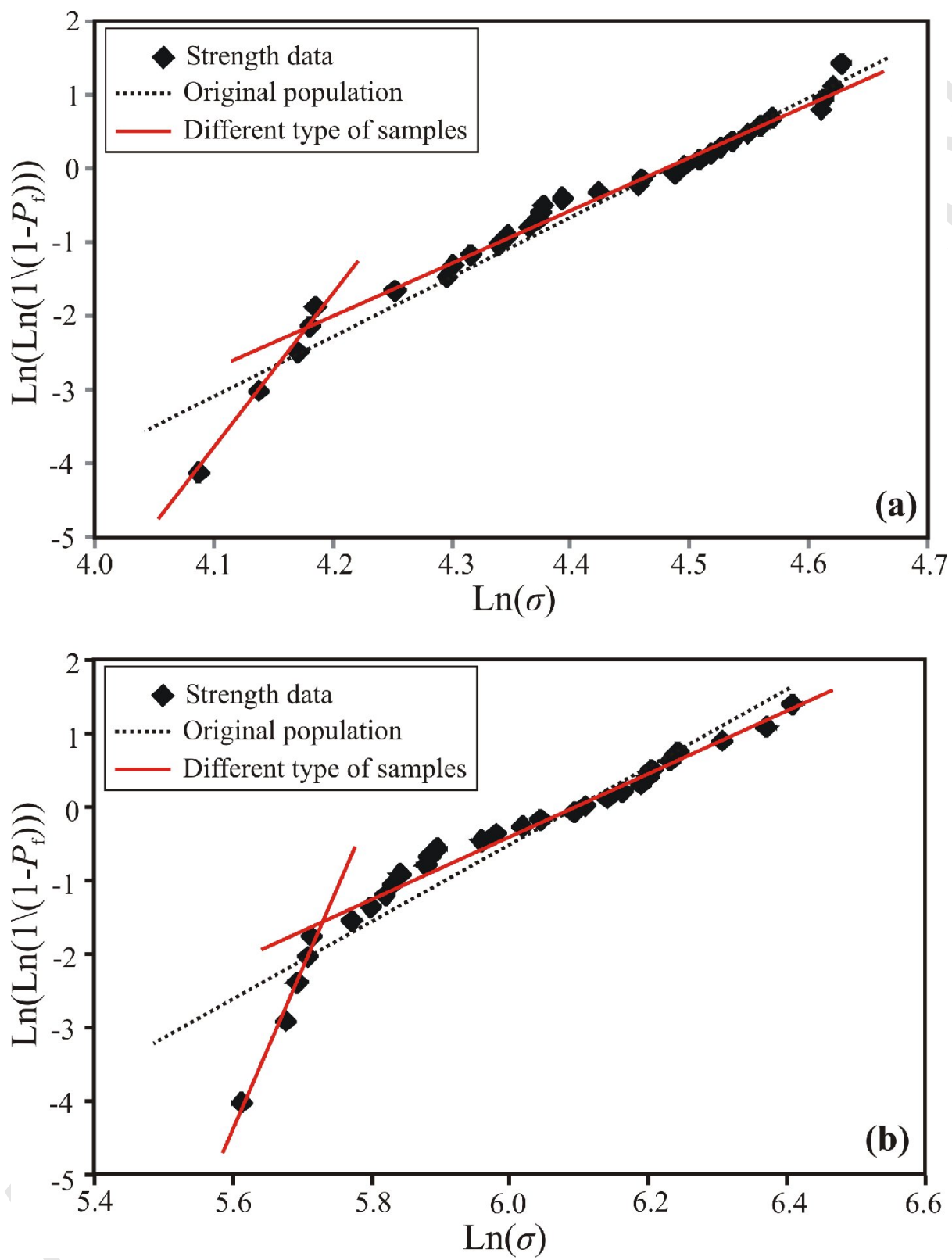

Fig. 9 

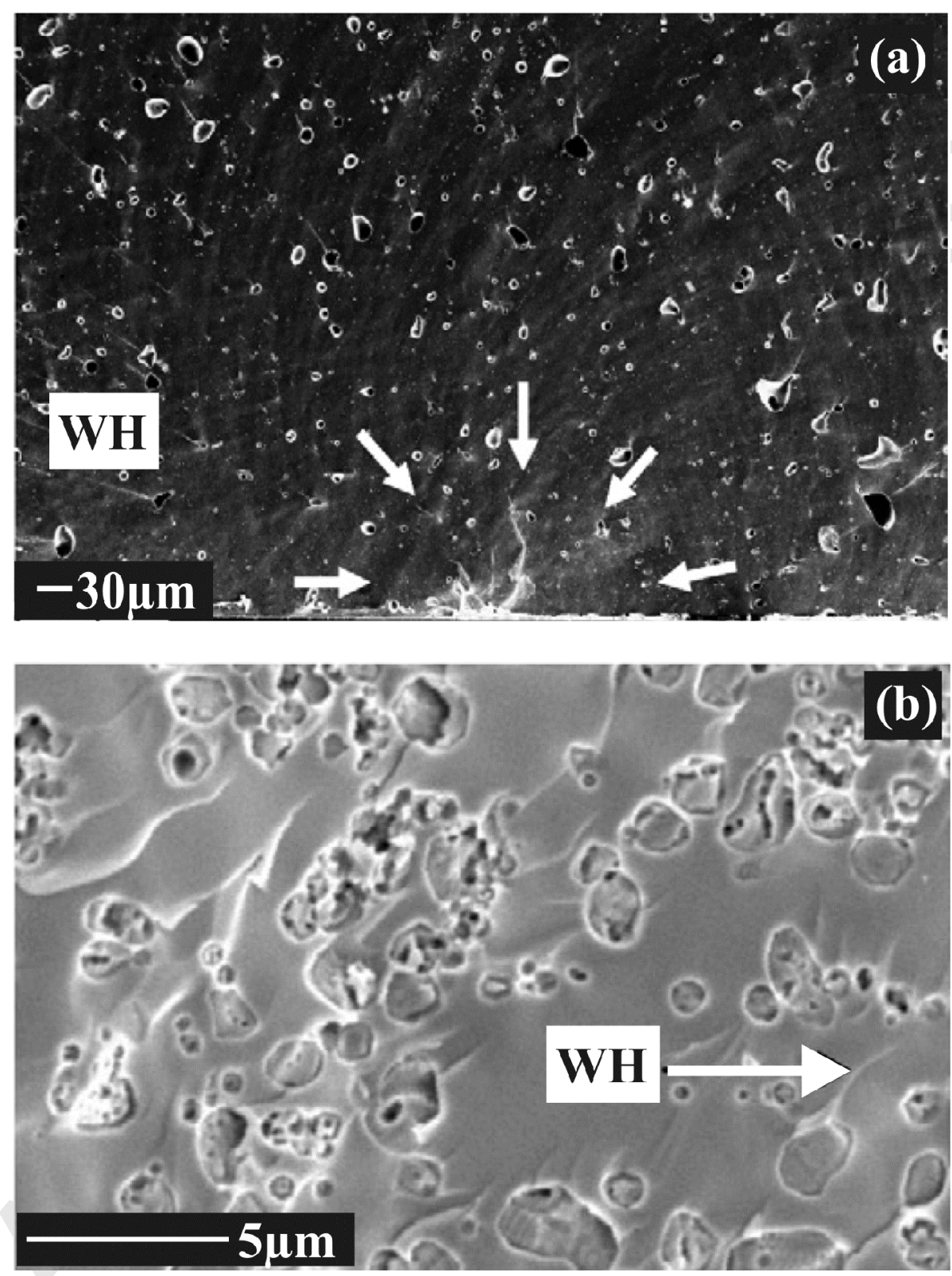

Fig. 10 


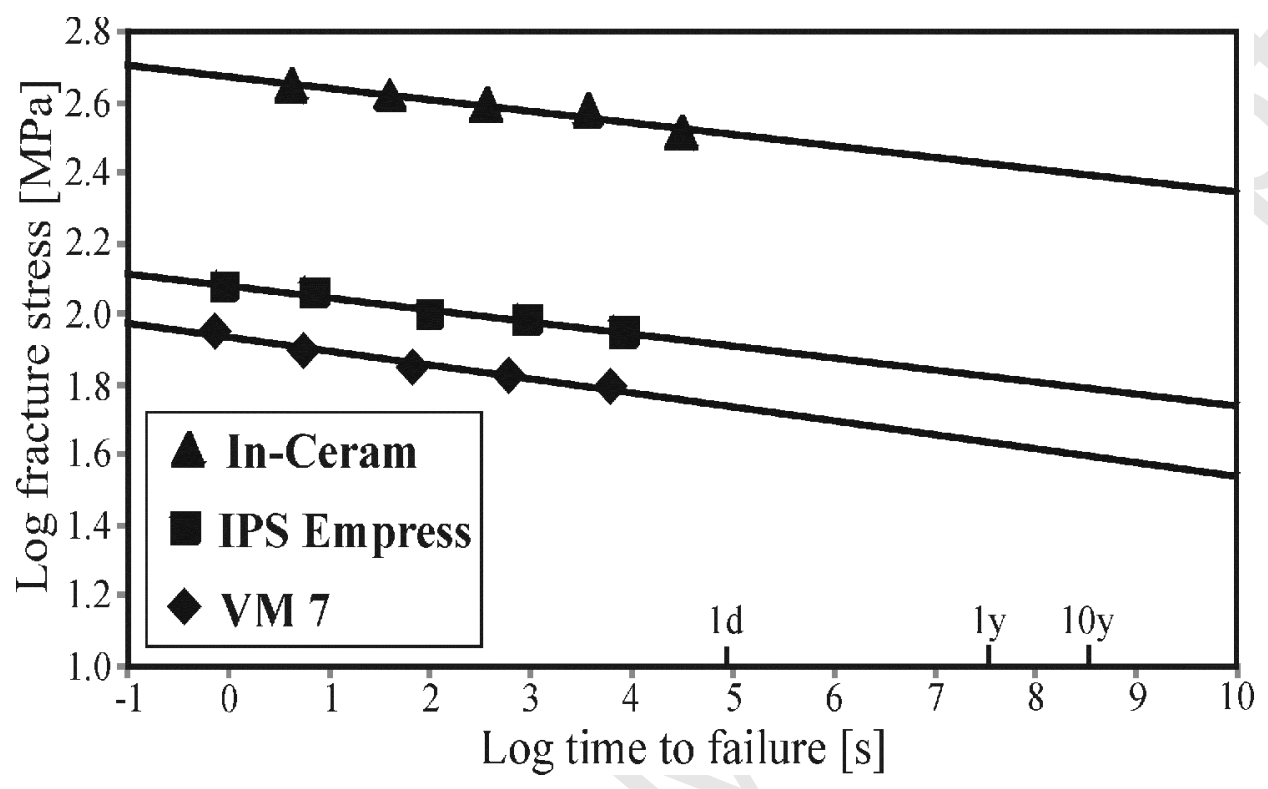

Fig. 11 